\title{
IMPLEMENTASI INTERNET OF THINGS UNTUK PEMANTAUAN KONDISI AIR HASIL DESTILASI OTOMATIS
}

\section{IMPLEMENTATION THE INTERNET OF THINGS FOR MONITORING OF AUTOMATIC DESTILLATION RESULTS}

\author{
Erdianto Ramadhan ${ }^{1}$, Ibrahim ${ }^{2}$, Gina Lova Sari $^{3}$ \\ ${ }^{123}$ Universitas Singaperbangsa Karawang \\ 1erdianto.ramadhan16151@student.unsika.ac.id, ${ }^{2}$ ibrahim@ft.unsika.ac.id, ${ }^{3}$ ginalovasari@gmail.com
}

\begin{abstract}
Abstrak
Tujuan dari penelitian ini adalah memperbarui system destilasi dengan merancang intenet of things untuk metode pemantauan kondisi air, sehingga kondisi air dapat dipantau melalui smartphone. Perancangan ini menggunakan mikrokontroler Arduino Uno sebagai kendali utama dari sistem destilasi dan dalam perancangan internet of things ini menggunakan sebuah modul ESP8266-01 sebagai komponen pengiriman data dari sistem ke aplikasi blynk yang ada di smartphone. Pemantauan kondisi air pada system destilasi ini ada beberapa kondisi yaitu, kondisi kandungan pH pada air, konsentrasi air (kadar garam) dan di lengkapi juga dengan pemantauan ketinggian air pada bak penampung. Berdasarkan hasil pengujian yang dilakukan, implementasi internet of things untuk pemantauan kondisi air hasil destilasi ini berjalan dengan baik dimana tidak ada perbedaan penampilan parameter sensor antara LCD dan aplikasi Blynk, namun pada modul ESP8266Olhanya memiliki jarak tempuh maksimal sejauh 25 meter, adapun untuk delay pada modul ESP8266-01 dengan kondisi sistem off memiliki rata-rata delay sebesar 8 menit pada malam hari, 10 menit pada pagi hari, dan 12 menit pada malam hari dengan provider yang memiliki kecepatan rata-rata internet $12 \mathrm{Mb} / \mathrm{s}$. Dari data yang dihasilkan pada proses pengiriman data dari sistem menuju aplikasi blynk membutuhkan bandwidth sebesar 93B dan trhougput dengan rata-rata 57bps.
\end{abstract}

\section{Kata kunci : IoT, Arduino Uno, ESP8266-01, Blynk}

\begin{abstract}
The purpose of this research is to update the distillation system by designing an internet of things for monitoring water conditions, so that water conditions can be monitored via a smartphone. This design uses the Arduino Uno microcontroller as the main control of the distillation system and in designing the internet of things, it uses an ESP8266-01 module as a component of sending data from the system to the Blynk application on the smartphone. Monitoring water conditions in this distillation system, there are several conditions, namely, the condition of the $\mathrm{pH}$ content in the water, the water concentration (salt content) and it is also equipped with monitoring the water level in the reservoir. Based on the results of the tests carried out, the implementation of the internet of things for monitoring the condition of the distilled water is going well where there is no difference in the appearance of sensor parameters between the LCD and the Blynk application, but the ESP8266-01 module only has a maximum distance of 25 meters, as for the delay. The ESP8266-01 module with the system off condition has an average delay of 8 minutes at night, 10 minutes in the morning, and 12 minutes at night with a provider that has an average internet speed of $12 \mathrm{Mb} / \mathrm{s}$. From the data generated in the process of sending data from the system to the blynk application, it requires a bandwidth of $93 B$ and an average of 57bps of input.
\end{abstract}

Keywords: IoT, Arduino Uno, ESP8266-01, Blynk 


\section{PENDAHULUAN}

Pemantauan kodnisi air adalah sebuah metode pengambilan sampel air secara berkala untuk menganalisa kondisi air dan karakteristiknya. Pemantauan kondisi air ini dilakukan dimana untuk meyakinkan bahwa sumber air tersebut aman untuk dikosumsi dan dapat digunakan untuk keperluan manusia dan hewan [1]. Peraturan yang dibuat oleh Mentri Kesehatan Republi Indonesia No.416 tahun 1990 telah menetapkan bahwa kualitas air yang baik untuk digunakan pada keperluan seharihari mengenai indicator parameter $\mathrm{pH}$ dan konsentrasi kepadatan zat pada air [2].

Penelitian serupa yang telah dilakukan ialah pemantauan kondisi air berbasis Internet of Things yang telah ada yaitu penelitian yang dilakukan oleh Trisna Dewi dkk mengenai "Sistem Pemantauan Kualitas Air Sungai di Kawasan Industri Berbasis WSN dan IoT" [3]. Penelitian ini mengajukan pemantauan kondisi air sungai pada kawasan industry yang menggunakan metode pemantauan berbasis internet of things dan Wireless Sensor Network yang di rancang menggunakan sensor $\mathrm{pH}$ electrode probe untuk mengukur pH, GE turbidity SKU SEN0189 untuk mengukur kekeruhan, dan DS18B20 untuk mengukur suhu air. Berikutnya Ilham Maulana Yusuf yang melakukan penelitian "Perancangan Alat pemantauan Kualitas Air (ATAIR) Berbasis Internat of

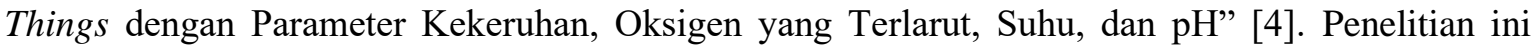
mengajukan tentang pemantauan kualitas air dengan beberapa parameter diantara kekeruhan, oksigen yang terlarut, suhu, dan $\mathrm{pH}$ air yang dilakukan langsung pada sungai cimahi yang berdekatan dengan industry tekstil.

Pemantauan kondisi air pada penelitian ini akan diterapkan pada sistem destilasi air laut menjadi air tawar, yang dimana pada proses pemantauan kodnisi air pada sistem destilasi masih bersifat konvensional. Sistem destilasi konvensional ini tentunya membutuhkan waktu dan tenaga lebih untuk pengambilan sampel air dan pengujian kondisi air tersebut.

Solusi dari permasalahan tersebut ialah dengan dibuatnya perancangan Internet of Things sebagai aplikasi pemantauan kondisi air pada sistem destilasi air laut yang menggunakan dua parameter yaitu, konsentrasi air (kadar garam) dan nilai pH air, serta dilengkapi dengan pemantauan ketinggian air pada penampungan sistem destilasi air laut. Perancangan Internet of Things ini merupakan metode pengiriman data melalui jaringan internet yang menggunakan modul ESP826601 sebagai komponen pengiriman data tersebut melalui jaringan intenet, yang nantinya data tersebut akan ditampilkan oleh aplikasi Blynk yang ada di smartphone, sehingga pemantauan kondisi air pada system destilasi ini dapat dipantau dari jarak jauh..

\section{DASAR TEORI/MATERIAL DAN METODOLOGI/PERANCANGAN}

\subsection{Dasar Teori}

\subsubsection{Arduino Uno}

Arduino Uno adalah sebuah board mikrokontroler yang menggunakan IC mikrokontroler ATmega 328 (datasheet). Arduino uno mempunyai 14 pin digital I/O (6 diantaranya dapat digunakan sebagai output PWM), 6 pin input analog, sebuha osilator, sebuah koneksi USB, sebuah power jack, dan sebuah tombol reset. Arduino uno sudah memuat semua yang dibutuhkan untuk menunjang keperluan mikrokontroler [5]. Hardware dalam Arduino memiliki prosesor atmel AVR dan mengguakan software bahasa sendiri yaitu bahasa C. Arduino uno diprogram menggunakan perangkat lunak yang bernama Arduino IDE. Arduino IDE dijalankan di PC dengan berbasis bahasa $\mathrm{C}$ yang telah didesain sedemikian rupa untuk mempermudah pengguna dalam memprogram Arduino uno. 


\subsubsection{ESP8266-01}

ESP8266-01 adalah sebuah chip yang sudah lengkap dimana didalamnya sudah termasuk processor, memori dan juga akses ke GPIO. Hal ini menyebabkan ESP8266-01 dapat secara langsung menggantikan Arduino dan ditambah lagi dengan kemampuannya untuk mensupport koneksi Wi-Fi secara langsung.

Tegangan kerja ESP8266-01 adalah sebesar 3.3V, sehingga untuk penggunaan mikrokontroler tambahannya dapat menggunakan board arduino yang memiliki fasilitas tengangan sumber 3.3V, akan tetapi akan lebih baik jika membuat secara terpisah level shifter untuk komunikasi dan sumber tegangan untuk wifi module ini. Karena wifi module ini dilengkapi dengan Mikrokontroler dan GPIO sehingga banyak orang yang mengembangkan firmware untuk dapat mengunakan module ini tanpa perangkat mikrokontroler tambahan.Firmware yang digunakan agar wifi module ini dapat bekerja standalone [6].

\subsubsection{Blynk}

Blynk merupakan dalah sebuah platform IoT berbasis iOS dan android untuk mengontrol arduino, raspberry $\mathrm{Pi}$, dan mikrokontroler sejenisnya melalui jaringan internet. Aplikasi ini menggunakan dashboard digital yang dapat membuat interface tampilan projek dengan fitur drag and drop widget [7]. Software blynk terdapat 3 komponen penting yaitu aplikasi, server, dan libraries. Aplikasi berguna sebagai interface untuk melakukan monitoring atau kontrol hardware yang telah terhubung dengan blynk, server berfungsi sebagai media penghubung antara smartphone dan hardware, sedangkan libraries berfungsi agar program yang telah dibuat dapat menghubungkan hardware dengan server secara otomatis.

\subsection{Metode Alat dan Bahan}

\subsubsection{Perangkat Lunak}

Berikut ini adalah beberapa perangkat lunak yang digunakan untuk perancangan system pada penelitian ini, diantaranya:

a. Arduino IDE, adalah sebuah aplikasi pemrograman yang menggunakan Bahasa pemrograman $\mathrm{C}++$ yang akan digunakan untuk membuat desain program pada system ini.

b. Blynk, adalah sebuah aplikasi smartphone yang nantinya akan digunakan sebagai aplikasi pemantauan pada system destilasi.

\subsubsection{Perangkat Keras}

Berikut ini adalah beberapa perangkat lunak yang digunakan untuk perancangan system pada penelitian ini, diantaranya:

a. Arduino Uno, sebagai pusat kontroler pada sistem pemantauan kondisi air

b. ESP8266-01, merupakan komponen yang digunakan untuk mengkoneksikan dan mentranfer data antara sistem dengan Wi-Fi yang ada di smartphone.

c. Sensor-sensor, sebagai inputan kondisi air yang akan dipantau. Sensor-sensor yang dugunakan berupa sensor $\mathrm{pH}$ sebagai pembacaan nilai $\mathrm{pH}$, sensor TDS sebagai pembacaan konsentrasi air (kadar garam), dan sensor ultrasonic sebagai pembacaan ketinggian air.

\subsection{Metodologi dan Perancangan}

\subsubsection{Metode Penelitian}

Metode penelitian yang akan digunakan pada penelitian ini akan ditampilkan pada flowchart pada gambar 1. 


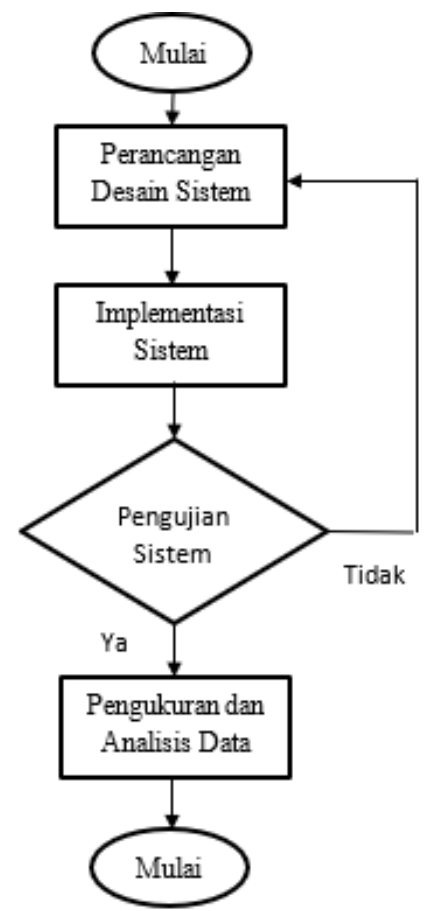

Gambar 1. Flowchart Metode Penelitian

\subsubsection{Perancangan Desain Sistem}

\section{a. Perancangan Perangkat Keras}

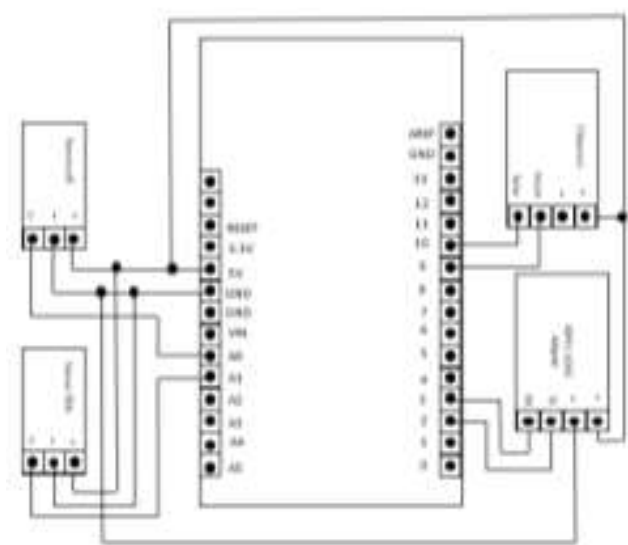

Gambar 2. Wiring Diagram Sistem Pemantauan

Gambar 2 merupakan sebuah wiring diagram pada sistem pemantauan yang dimana pada modul ESP8266-01 menggunakan adaptor untuk mengurangi pin input output nya menjadi 4 pin yaitu pin tx, tx, input, dan ground. Adapun pengalamatan pin ke Arduino sebagai berikut:

- Pin input sensor pH ke pin A0 pada Arduino

- Pin input sensor TDS ke pin A1 pada Arduino

- Pin triger dan echo pada sensor ultrasonic ke pin D9 dan D10 pada Arduino

- Pin tx dan rx pada ESP8266-01 ke pin D2 dan D3 pada Arduino 


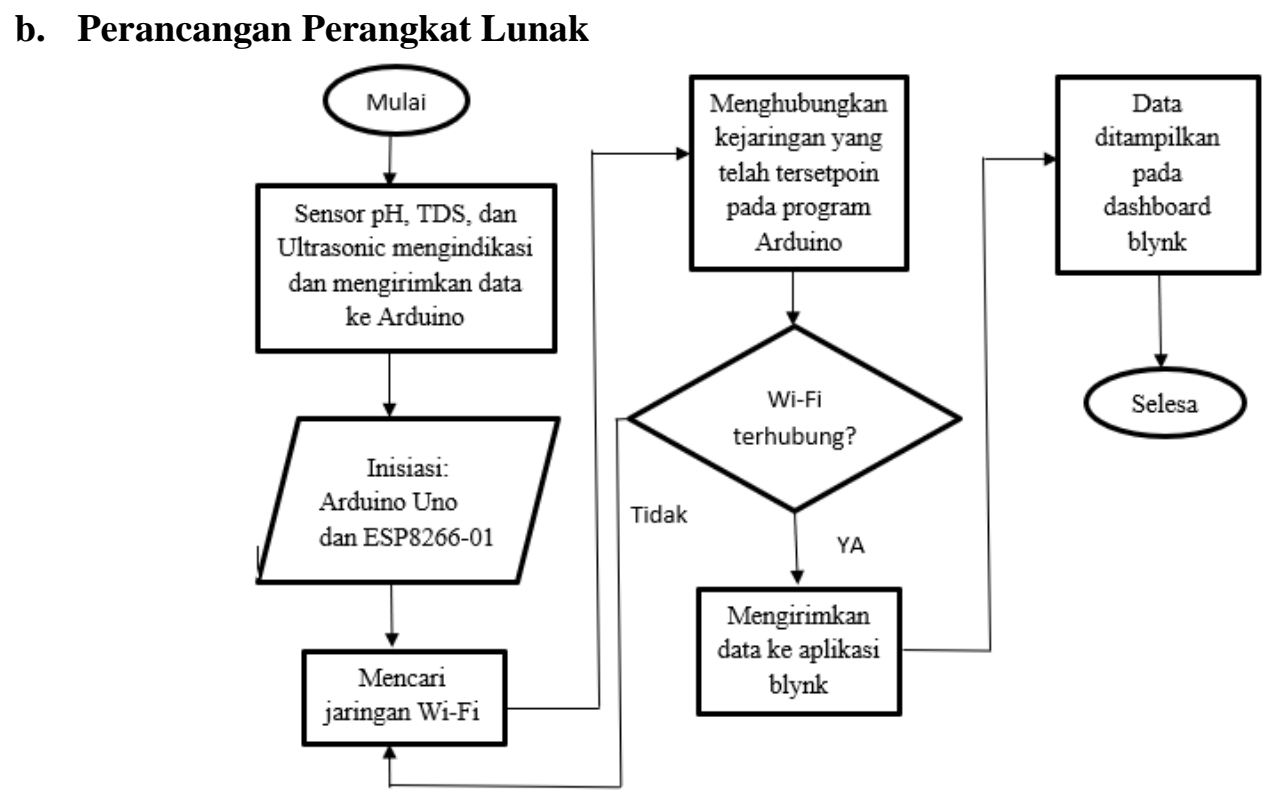

Gambar 3. Flowchart Perancangan Perangkat Lunak

Perangkat lunak yang digunakan dalam penelitian ini ada 2 aplikasi yaitu aplikasi Arduino IDE sebagai aplikasi pembuatan program dan aplikasi Blynk pada smartphone sebagai aplikasi pemantauannya. Alur kerja dari sistem dimulai ketika mesin dihidupkan lalu sensor ultrasonic, $\mathrm{pH}$, dan TDS membaca sesuai dengan fungsi nya yang menghasilkan sebuah data-data analog yang kemudian dikirimkan ke Arduino Uno untuk diproses dan dari Arduino Uno dikirimkan ke modul ESP8266-01. Data analog yang dikirimkan Arduino Uno disimpan sementara pada modul ESP8266-01 sampai modul ESP8266-01 dapat terkoneksi dengan smartphone yang telah tersetpoin pada program, setelah ESP8266-01 terkoneksi dengan smartphone maka data analog dikirimkan dari modul ESP8266-01 ke aplikasi blynk yang ada di smarphone.

\section{HASIL dan PEMBAHASAN}

\subsection{Implementasi Sistem Pemantauan}

Implementasi sistem adalah proses perancangan dan pengujian program untuk ESP8266-01 sebagai aplikasi pemantauan kondisi air pada sistem destilasi apakah dapat berjalan dengan baik dan menampilkan parameter sesuai dengan yang telah terset point oleh program.

Gambar 4 ini merupakan program untuk modul ESP8266-01 dengan set point token pada aplikasi blynk, nama hotspot pada smartphone, dan password hotspot pada smartphone yang akan digunakan. Gambar 5 merupakan tampilan pada aplikasi blink dimana pada bagian atas adalah super chart yang berfungsi menampilkan nilai-nilai dari data yang dikirimkan oleh sensor $\mathrm{pH}$ dan sensor TDS berupa grafik. Bagian tengah pada tampilan blynk adalah gauge yang berfungsi menampilkan nilai-nilai dari data yang dikirimkan oleh sensor $\mathrm{pH}$ dan sensor TDS berupa satuan angka. Bagian paling bawah adalah volume yang berfungsi menampilkan keadaan air pada penampungan. 


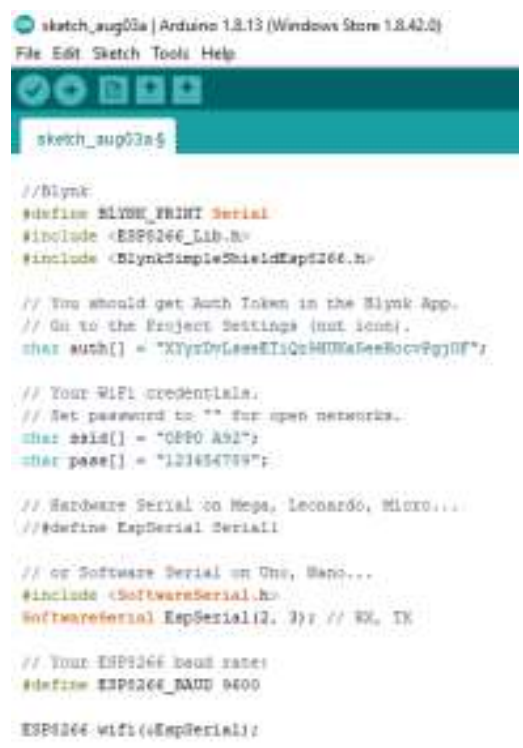

Gambar 4. Program ESP8266-01 pada Arduino IDE

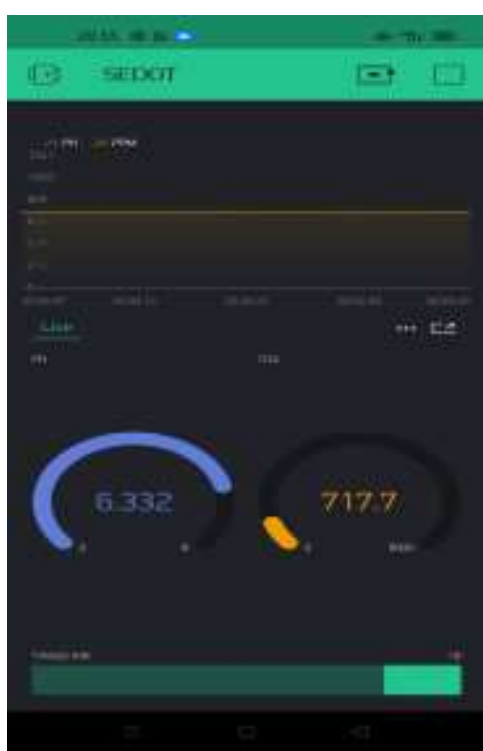

Gambar 5. Tampilan Aplikasi Pemantauan pada sistem destilasi air laut

\subsection{Pengujian Kesesuaian Antara LCD dengan Aplikasi Blynk}

Tabel 1 Hasil Pengujian Keselarasan antara LCD dengan Aplikasi Blynk

\begin{tabular}{|c|c|c|c|c|c|c|c|}
\hline \multirow{2}{*}{$\begin{array}{c}\text { Detik } \\
\text { Ke- }\end{array}$} & \multicolumn{3}{|c|}{ Tampilan LCD } & \multicolumn{3}{|c|}{ Tampilan Blynk } & Kondisi \\
\cline { 2 - 8 } & Sensor & Sensor TDS & $\begin{array}{c}\text { Sensor } \\
\text { Ultrasonic } \\
(\mathbf{P P M})\end{array}$ & $\begin{array}{c}\text { Sensor pH } \\
(\mathbf{C m})\end{array}$ & $\begin{array}{c}\text { Sensor TDS } \\
(\mathbf{p H}) \\
(\mathbf{P P M})\end{array}$ & $\begin{array}{c}\text { Sensor } \\
\text { Ultrasonic } \\
(\mathbf{C m})\end{array}$ & \\
\hline 1 & 6,3 & 759 & 15 & 6,3 & 759 & 15 & Terbaca \\
\hline 2 & 6,3 & 743 & 15 & 6,3 & 743 & 15 & Terbaca \\
\hline 3 & 6,2 & 758 & 16 & 6,2 & 758 & 16 & Terbaca \\
\hline 4 & 6,1 & 759 & 15 & 6,1 & 759 & 15 & Terbaca \\
\hline 5 & 6,3 & 759 & 16 & 6,3 & 759 & 16 & Terbaca \\
\hline 6 & 6,2 & 735 & 15 & 6,2 & 735 & 15 & Terbaca \\
\hline
\end{tabular}

Table 1 merupakan hasil pengujian yang ditampilkan LCD baik itu nilai sensor $\mathrm{pH}$, sensor TDS, dan Sensor Ultrasonic sama dengan apa yang ditampilkan pada aplikasi blynk yang ada di smartphone, dan untuk delaynya sesuai dengan apa yang telah terset poin, dengan demikian tampilan LCD dan aplikasi Blynk selalu sama baik nilai ataupun delay. Adapun yang membedakan nilai sensor pH dan sensor TDS setiap detiknya adalah karakteristik dari sensor itu sendiri, jadi perlu mengambil nilai rata-rata dari beberapa sempel yang di ambil. 
Jurnal Electro Luceat [November $][2020]$

3.3 Pengujian Delay pada ESP8266-01 Untuk Terkoneksi pada Aplikasi Blynk

Tabel 2 Hasil pengujian kecepatan ESP8266 dengan kecepatan rata-rata internet $12 \mathrm{Mb} / \mathrm{s}$

\begin{tabular}{|c|c|c|c|c|}
\hline Jam & Jarak & $\begin{array}{c}\text { Kecepatan Koneksi } \\
\text { ESP8266 dengan Wifi } \\
\text { (s) }\end{array}$ & $\begin{array}{c}\text { Kecepatan Koneksi } \\
\text { ESP8266 dengan Blynk } \\
\text { (s) }\end{array}$ & Kondisi \\
\hline \multirow{3}{*}{01.00} & $30 \mathrm{~cm}$ & 02.09 & 09.05 & Terhubung \\
\hline & 1 meter & 02.76 & 09.82 & Terhubung \\
\hline & 3 meter & 02.36 & 08.02 & Terhubung \\
\hline \multirow{3}{*}{10.00} & $30 \mathrm{~cm}$ & 03.22 & 10.53 & Terhubung \\
\hline & 1 meter & 03.76 & 10.61 & Terhubung \\
\hline & 3 meter & 03.04 & 09.55 & Terhubung \\
\hline \multirow{3}{*}{17.00} & $30 \mathrm{~cm}$ & 04.13 & 10.64 & Terhubung \\
\hline & 1 meter & 04.37 & 10.47 & Terhubung \\
\hline & 3 meter & 03.85 & 09.16 & Terhubung \\
\hline
\end{tabular}

Tabel 3 merupakan hasil pengujian serta pengamatan kecepatan atau delay pada modul ESP8266-01dengan rata-rata kecepatan internet $12 \mathrm{Mb} / \mathrm{s}$, sehingga pada kecepatan internet tersebut meiliki nilai rata-rata delay selama 2 menit pada malah hari, 3 menit pada pagi hari, dan 4 menit pada sore hari. Perbedaan kecepatan konektivitas atau delay pada modul ESP8266-01 dipengaruhi oleh jumlah pengguna yang dimana pada malam lebih sedikit dari pada pengguna pada pagi dan sore hari, dan untuk beban pucak terjadi pada sore hari yang menyebabkan delay ESP8266-01 memiliki waktu yang lebih lama. Jarak tidak mempengaruhi kecepatan atau delay pada modul ESP8266-01, hal ini dapat di lihat pada table 2 bahwa pada jarak 30cm, 1 meter, dan 3 meter tidak memiliki perbedaan delay.

Kecepatan internet tentunya sangat mempengaruhi delay pada modul ESP8266-01 tersebut, dikarnakan semakin cepat kecepatan internet maka semakin kecil pula delay yang dialami oleh modul ESP8266-01. Seperti yang dilansir oleh kompas.com bahwa nilai kecepatan rata-rata internet $12 \mathrm{Mb} / \mathrm{s}$ dimiliki oleh provider Telkomsel [8].

\subsection{Respon Jarak pada ESP8266-01 Agar Tetap Terkoneksi}

Tabel 3 Pengujian Respon Jarak ESP8266 agar tetap terkoneksi dengan Blynk

\begin{tabular}{|c|c|c|c|}
\hline No & Jarak (m) & Delay Saat Alat Diaktifkan (s) & Respon \\
\hline 1 & 3 & 10 & Terhubung \\
\hline 2 & 6 & 10 & Terhubung \\
\hline 3 & 9 & 9 & Terhubung \\
\hline 4 & 12 & 10 & Terhubung \\
\hline 5 & 15 & 11 & Terhubung \\
\hline 6 & 21 & 11 & Terhubung \\
\hline 7 & 25 & 10 & Terhubung \\
\hline 8 & 26 & 0 & Tidak Terhubungan \\
\hline
\end{tabular}


Table 3 menampilkan bahwa pada jarak 26 meter modul ESP8266 tidak lagi dapat terkoneksi. Hal ini disebabkan oleh hasil uji coba trail eror dalam pengukuran jarak tempuh modul ESP8266-01 yang hanya mampu menempuh jarak $25 \mathrm{~m}$.

\subsection{Pengujian Bandwidht dan Througput}

\section{a. Pengujian Bandwidth}

Hasil pengujian didapatkan besar data yang diperlukan dalam satu detik petama yaitu 93B dan untuk satu detik seterusnya membutuhkan rata" besar data 5,6B. Adapun cara perhitugan untuk mengetahui bandwidth adalah:

$$
\begin{aligned}
& \text { Jumlah pengguna } * \text { besar data maksimal yang dibutuhkan } \\
& \qquad 1 \times 93 \mathrm{~B}=93 \mathrm{~B}
\end{aligned}
$$

Jadi untuk lebar bandwidth pada proses prngiriman data dari ESP8266 ke blynk dalam satu detik transfer data adalah 93B

\section{b. Pengujian Throughput}

Tabel 5 Nilai Pengujian Througput

\begin{tabular}{|c|c|c|}
\hline Waktu (s) & Besar data yang diterima & Througput \\
\hline 10 & $597 \mathrm{~B}$ & $59,7 \mathrm{bps}$ \\
\hline 25 & $1.436 \mathrm{~B}$ & $57,44 \mathrm{bps}$ \\
\hline 60 & $3.675 \mathrm{~B}$ & 61,25 \\
\hline
\end{tabular}

Hasil data pada table 7 diatas menjelaskan bahwa nilai Thorugput berbeda-beda pada setiap pengambilan sampel waktu tertentu. Hal ini disebabkan oleh jumlah data pada parameter sensor yang di kirim dari ESP8266 ke aplikasi blynk, adapun yang paling mempengaruhi perbedaan nilai adalah menurunnya kecepatan internet pada provider yang digunakan yang disebabkan banyaknya user yang memakai koneksi internet pada saat itu.

\section{KESIMPULAN}

Perancangan monitoring sistem destilasi air ini menggunakan beberapa komponen diantaranya: Arduino uno, ESP8266-01, dan aplikasi blynk pada smartphone, yang nantinya pin Tx pada modul ESP8266-01 akan terhubung ke pin 2 pada Arduino dan pin Rx akan terhubung pada pin 3 arduino. Kemudian yang akan di tampilkan pada aplikasi blynk adalah: gauge untuk menampilkan nilai parameter pada sensor $\mathrm{pH}$ dan TDS, superchart untuk menampilkan grafik, dan volume untuk menampilkan ketinggian air pada sensor ultrasonic. Tampilan pada LCD dengan aplikasi Blynk tidak memiliki perbadaan baik dari nilai" sensor maupun delay dengan kata lain efektivitas antara penampilan nilai-nilai pada LCD dan aplikasi Blynk adalah 100\%. Provider telkomsel memiliki delay dengan nilai delay 2 menit pada malam hari di karnakan memiliki kecepatan internet $12 \mathrm{Mb} / \mathrm{s}$. Jarak maksimal yang dapat ditempuh modul ESP8266-01 agar tetap terkoneksi sejauh 25 meter. Nilai bandwith dan thorugput pada ESP8266 dapat dilihat dari seberapa besar data internet yang dibutuhkan oleh ESP8266 untuk mentransfer data ke aplikasi Blynk, dengan besar nilai bandwidth 93B dan nilai kecepatan rata-rata troughput sebesar 57bps. 


\section{DAFTAR PUSTAKA}

[1] Dewi, Trisiani. Maulana, Nirfan. Rafi, Adnan. 2019. Sistem Pemantauan Kualitas Air Sungai di Kawasan Industri Berbasis WSN dan IoT. Jurnal Teknologi Rekayasa, Vol. 4, No. 2, Hal. 283-292.

[2] Peraturan Mentri Kesehatan (Permenkes no. 416/MENKES/PER/IX/1990). [Online]. Tersedia: https://www.depkes.go.id/.

[3] Dewi, Trisiani. Maulana, Nirfan. Rafi, Adnan. 2019. Sistem Pemantauan Kualitas Air Sungai di Kawasan Industri Berbasis WSN dan IoT. Jurnal Teknologi Rekayasa, Vol. 4, No. 2, Hal. 283-292.

[4] Yusuf, Ilham Maulana. 2018. "Perancangan Alat pemantauan Kualitas Air (ATAIR) Berbasis Internat of Things dengan Parameter Kekeruhan, Oksigen yang Terlarut, Suhu, dan pH". Skripsi. Tidak Diterbitkan. Program Studi Teknik Lingkungan, Fakultas Teknik, Universitas Pasudan: Bandung.

[5] Idhar. 2017. Embedded System And Robotics. Makassar: Universitas Negeri Makassar.

[6] Arwani, Fahad. Priyono, 2015. Sistem Management Bandwidh Pada Jaringan KomunikasiVoice Over InternetProtoccol (VoIP) Dengan Metode Load Balancing. Fakultas Teknik Elektro. Universitas Brawijya. Malang.

[7] Riswandi. 2019. Sistem Kontrol Vertical Garden Menggunakan NODEMCU ESP8266 Berbasis Android. Makassar: UIN Alauddin Makassar.

[8] Clinten, Bill. 2020. "Telkomsel Tercepat dan Smartfren Terluas Versi Opensignal”. Kompas.com. 